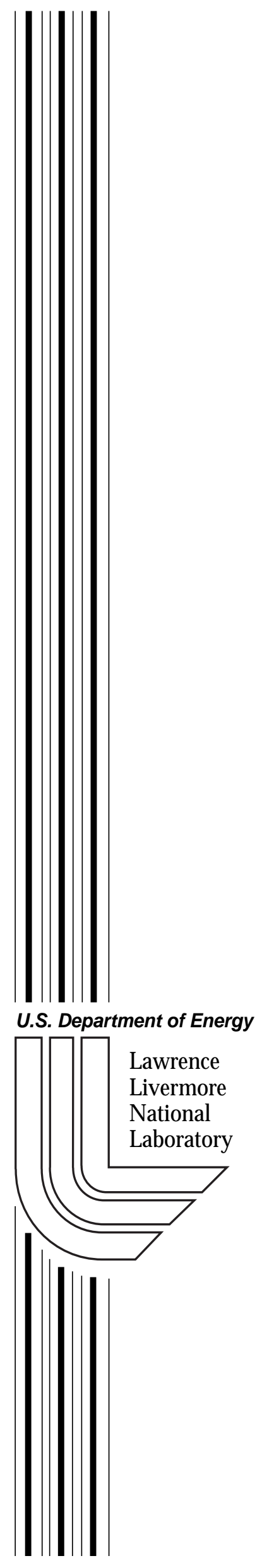

UCRL-ID-154783

\title{
Scoping Inventory Calculations for the Rare Isotope Accelerator
}

\author{
L. E. Ahle and J. L. Boles
}

July 25, 2003 
This document was prepared as an account of work sponsored by an agency of the United States Government. Neither the United States Government nor the University of California nor any of their employees, makes any warranty, express or implied, or assumes any legal liability or responsibility for the accuracy, completeness, or usefulness of any information, apparatus, product, or process disclosed, or represents that its use would not infringe privately owned rights. Reference herein to any specific commercial product, process, or service by trade name, trademark, manufacturer, or otherwise, does not necessarily constitute or imply its endorsement, recommendation, or favoring by the United States Government or the University of California. The views and opinions of authors expressed herein do not necessarily state or reflect those of the United States Government or the University of California, and shall not be used for advertising or product endorsement purposes.

This work was performed under the auspices of the U.S. Department of Energy by University of California, Lawrence Livermore National Laboratory under Contract W-7405-Eng-48. 


\title{
Scoping Inventory Calculations for the Rare Isotope Accelerator
}

\author{
Larry Ahle and Jason Boles \\ Lawrence Livermore National Laboratory
}

July 25, 2003

\section{Executive Summary}

This document is a report on our activities in FY03 exploring nuclear safety and hazard analysis issues relevant to the Rare Isotope Accelerator (RIA). It is not clear whether DOE will classify the RIA as an accelerator facility subject to the accelerator-specific safety requirements of DOE Order 420.2A or as a nonreactor nuclear facility subject to the requirements of 10 CFR 830 . The final outcome of this issue will have significant impact on the construction and operation of the facility and the quality assurance requirements for items or services that may affect nuclear safety. The resolution of this issue will be an important earlier decision for the RIA project team and will require early consultation with the appropriate DOE authorities. For nuclear facilities, facility hazard classification depends on the inventory of releasable radionuclides; therefore, some simplistic, scoping inventory calculations for some assumed targets and beams are done to estimate the hazard category of RIA if it is declared a nuclear facility. These calculations show that for the scenarios analyzed, RIA would produce sufficient quantities of radionuclides to be classified as a Category 3 nuclear facility. Over the lifetime of RIA operations, it may be possible to build up Category 2 quantities of ${ }^{227} \mathrm{Ac}$ and ${ }^{228} \mathrm{Th}$. A storage building, separate from the driver, target, and experimental buildings, used to store and isolate accumulated targets and other hardware, can mitigate the potential impact on RIA. The more onerous requirements of Category 2 facilities would only be imposed on the storage facility and not on the rest of the RIA facilities. Some of the differences in a category 2 and category 3 facility are discussed in Appendix 1.

\section{Nuclear Facility or Accelerator Facility?}

Is the Rare Isotope Accelerator to be considered a nuclear facility and subject to hazard classification or an accelerator facility? is the first question to be answered when approaching the safety analysis. In other words is RIA subject to the requirements of 10 CFR 830, Nuclear Safety Management or DOE Order 420.2A, Safety of Accelerator Facilities. The scope of 10 CFR 830 is the safety of DOE nuclear facilities, such as reactors or other facilities that involve radioactive and/or fissionable materials in such form and quantity that a nuclear hazard potentially exists to workers, the public, or the environment, but does not include accelerators and their operations. DOE Order 420.2A establishes accelerator-specific safety requirements which, when supplemented by other applicable safety and health requirements, serves to prevent injuries and illnesses associated with DOE or NNSA accelerator operations. Facilities for which DOE Order 5480.23, Nuclear Safety Analysis Reports, is applied are excluded from DOE Order 420.2A. 10 CFR 830 is the successor document to DOE Order 5480.23.

RIA could be subject to hazard classification because RIA may have the potential for significant radiological consequences, based on expected radiological inventories and possible release mechanisms. A Category 3 nuclear facility has the potential for significant localized consequences, and a Category 2 
nuclear facility has the potential for significant on-site consequences beyond localized consequences. RIA may not be subject to hazard classification because RIA is an accelerator facility, which is specifically excluded from the definition of a nonreactor nuclear facility and, therefore, is outside the scope of 10 CFR 830, including hazard classification. David Pinkston of LLNL, who co-wrote DOESTD-1027-92, Hazard Categorization And Accident Analysis Techniques For Compliance With DOE Order 5480.23, Nuclear Safety Analysis Reports, agrees with this interpretation.

However, the determination of this first question is often based on politics, management issues, and negotiations with DOE and not just hazard analysis. NIF for instance did its safety analysis assuming it was a category 3 nuclear facility while it was believed and confirmed to be a non-nuclear facility. For the Spallation Neutron Source (SNS), currently under construction at Oak Ridge National Laboratory, the decision was made in consultation with DOE not to pursue the accelerator facility option and treat it as a Category 2 facility. The basis for classifying SNS as a Category 2 nuclear facility during high power operation is the following:

- neutronic calculations showing SNS radionuclide inventory exceeding the curie threshold for Category 2 (dominated by Hg-203, Hg-197, and Gd-148), and

- the target material, mercury, will boil at temperatures that could hypothetically be achieved in a fire.

Making this decision will be one of the important early decisions for the RIA project team, and a crucial part of the decision making process will be early contact with the appropriate DOE officials.

\section{Phased Operation and Facility Segmentation}

The Spallation Neutron Source may also offer some guidance on how the safety basis of the RIA facility could be managed. The approval of safety documents and authorization to commission and operate the SNS facility is divided into two phases. ${ }^{1}$ The first phase is associated with commissioning and low power operation of all SNS facility systems, including the proton accelerator, storage ring, beam stops, and target systems (prior to radioisotope accumulation which transitions the target system into a nuclear facility). The SNS Project Manager is responsible for establishing and approving the safety basis and operations for this phase in accordance with DOE Order 420.2A. The second phase is associated with high power operation of the facility, at which time certain target building systems will transition into a nuclear facility (successively, Category 3 and then Category 2) as the radioisotope inventory accumulates. This transition is planned to occur about six months to one year after project completion. For the SNS Project, Office of Science has chosen to grant authority to approve safety documents for Category 2 nuclear facilities to the SNS Project Manager.

An additional approach that SNS uses is facility "segmentation." Their use of segmentation allows them to exclude the accelerator building and experimental halls from being subject to the requirements imposed on Category 2 nuclear facilities, so that only the target building is categorized as a nuclear facility. The guidelines for segmentation are provided in DOE-STD-1027-92. In cases where hazards

\footnotetext{
${ }^{1}$ Dehmer, P.M., Associate Director of the Office of Science for the Office of Basic Energy Sciences, April 25, 2002, memorandum to R.L. Orbach, Director, Office of Science, subject ACTION: Approve the Annual Update to Appendix A of the Project Execution Plan (PEP) for the Spallation Neutron Source (SNS) Project, DOE, Germantown, MD.
} 
vary greatly in different locations within a facility, the concept of independent facility segments can be applied where facility features preclude bringing hazardous material together or causing harmful interaction from a common severe phenomenon. This concept allows facilities to avoid placing the excessive requirements derived for segments containing Category 3 or 2 amounts of material on colocated segments. In order to utilize segmentation, the independence of facility segments must be demonstrated in the facility's Documented Safety Analysis (DSA) to the extent that hazardous material in one segment could not interact with hazardous materials in other segments during a common severe phenomenon. For example, independence of HVAC and piping must exist in order to demonstrate independence for facility segmentation purposes. For segments that share a common wall, fire rated walls and doors are usually used.

One advantage SNS has over RIA in establishing segmentation is that in normal SNS operations, the radiological inventories are contained in a single location, the target. This is not the case for RIA whose concept is based on the idea of radioactive material leaving the target and transported to different areas of the facility. This may have its biggest impact on whether the experimental areas could be considered accelerator facilities while the target area a Category 2 or 3 nuclear facility.

\section{An Unreviewed Safety Question Procedure Would Be Followed for Beam-Target Configurations Not in the Documented Safety Analysis}

Included in the DSA is a systematic identification of the hazards and an evaluation of normal, abnormal, and accident conditions associated with the facility. Based on these hazard and accident analyses, hazard controls are derived to ensure adequate protection of workers, the public, and the environment. However, due to the expected flexibility of RIA, it would be difficult to analyze all possible beam-target configurations. If DOE declares RIA a nuclear facility subject to 10 CFR 830, it is expected that the DSA for a RIA facility would include radioisotope inventory calculations only for a few representative beam-target configurations. For beam-target configurations that are not specifically analyzed in the DSA, a DOE-approved Unreviewed Safety Question (USQ) procedure would be established and followed, as required by 10 CFR 830.203 for nuclear facilities.

The USQ process is used to determine the impact of a proposed activity on the facility's DSA. A proposed activity is a temporary or permanent change (e.g., hardware change) in the facility as described in the DSA, a temporary or permanent change in procedures as described in the DSA, a test or experiment not described in the existing DSA, or a potential inadequacy in the DSA. There are specific criteria that are considered to determine the impact of a proposed activity, but the process can be boiled down to the following: does the proposed activity increase the risk of an accident beyond what is accepted in the DSA or reduce the DSA's margin of safety? If the new configuration can be accommodated within the existing safety basis, then the approval of only facility management would be required prior to operation of the new configuration, and DOE approval would not be required. If not, DOE approval is required. The analysis of the proposed change must be done with the same rigor as the analysis in the DSA. Note that the facility's USQ process is subject to annual review and audit by DOE.

\section{Scoping Radioisotope Production Calculations}


Since the possibility exist for RIA to be subject to hazard categorization, a preliminary analysis of a few potential beam-target configurations is performed to make an initial estimate of radiological inventory levels in order to determine whether RIA should a Category 2 or 3 facility. The difference in requirements for Category 2 and 3 facilities is substantial, some of which are discussed in Appendix 1.

Table 1 lists the required production rates to reach Category 2 inventory limits assuming a one day, seven day, twenty-eight day, one year, and twenty year irradiation time. Only isotopes requiring production rates of less than $10^{16}$ atoms/second are listed since these are the only ones to contribute significantly to the inventories at RIA given the expected production rates. The rates in table 1 were determined from the limits given in DOE-STD-1027-92 except for ${ }^{32} \mathrm{P}$. LA-12846-MS, Specific Activities, a LANL document referred to by DOE-STD-1027-92 as a more complete list of specific activities, lists the Category 2 threshold for ${ }^{32} \mathrm{P}$ at a factor of 100 higher than the DOE document. By following the methods outlined in DOE-STD-1027-92 and using the same input, the Category 2 threshold listed in DOE-STD-1027-92 appears to be in error. Therefore the higher number is used.

The first observation is the small number of isotopes left to play a significant role in the categorization, especially for the short irradiation times. Some of the isotopes listed can be disregarded because the $Z$ of the nucleus is significantly greater than 92 . Since the highest $Z$ beam and target presently planned for RIA is uranium, the production rates for $Z$ greater than 92 nuclei should be small compared to the production rates listed in the table. Pu and $\mathrm{Np}$ are possible exceptions to this especially for the two-step ISOL target. Therefore isotopes of $\mathrm{Am}, \mathrm{Cm}$, and $\mathrm{Cf}$ can be ignored.

It also is apparent that over 20 years inventories of long-lived actinide isotopes, such as ${ }^{227} \mathrm{Ac}$ and ${ }^{228} \mathrm{Th}$, can build up to the point at which their inventories are of concern. The required production rates for these isotopes fall with time, while the shorter-lived isotopes maintain a relatively constant required production rate. When comparing to the required production rate over twenty years, it is important to consider machine availability and how often a specific configuration is run on RIA. While this will decrease the expected average production rate over 20 years, the required production rate for ${ }^{227} \mathrm{Ac}$ of $3.4 \times 10^{11} \mathrm{pps}$ is low enough to cause concern. One possibility to deal with these isotopes is to remove them periodically from the RIA target building area to a co-located storage area. How this would affect the inventories from the ISOL target area and fragmentation line is described below. The storage facility could be designed as a Category 2 facility, but initially operated only as a Category 3 facility. Only at a later time if the inventories warrant would it be operated as a Category 2 facility. All of this would be independent of the RIA facility itself. In short, a separate storage area would provide greater flexibility in handling inventories and keeping the RIA facility below Category 2 limit. We believe this idea has already been somewhat discussed in the RIA community and we strongly endorse this idea. 
Table 1. Production Rate (atoms/s) Required for a Category 2 Amount

\begin{tabular}{|c|c|c|c|c|c|c|c|c|c|}
\hline \multicolumn{2}{|c|}{ Isotope 1 day exposure duration } & Isotope & $\begin{array}{c}7 \text { day } \\
\text { exposure } \\
\text { duration }\end{array}$ & Isotope & $\begin{array}{c}28 \text { day } \\
\text { exposure } \\
\text { duration }\end{array}$ & Isotope & $\begin{array}{c}65 \text { day } \\
\text { exposure } \\
\text { duration }\end{array}$ & Isotope & $\begin{array}{l}7300 \text { day } \\
\text { exposure } \\
\text { duration }\end{array}$ \\
\hline $\mid-131$ & $7.8 \mathrm{E}+14$ & $\mid-131$ & $1.4 \mathrm{E}+14$ & Ac-227 & $6.5 \mathrm{E}+13$ & Ac-227 & $5.0 \mathrm{E}+12$ & Ac-227 & $3.4 \mathrm{E}+11$ \\
\hline Ac-225 & $1.6 \mathrm{E}+15$ & Ac-227 & $2.6 \mathrm{E}+14$ & $\mid-131$ & $7.1 \mathrm{E}+13$ & Th-228 & $1.1 \mathrm{E}+13$ & Th-228 & $3.4 \mathrm{E}+12$ \\
\hline Ac-227 & $1.8 \mathrm{E}+15$ & Ac-225 & $2.7 \mathrm{E}+14$ & Po-210 & $9.9 \mathrm{E}+13$ & Po-210 & $1.5 \mathrm{E}+13$ & Cf-252 & $8.3 E+12$ \\
\hline Ra-224 & $2.1 \mathrm{E}+15$ & Po-210 & $3.8 \mathrm{E}+14$ & Th-228 & $1.2 \mathrm{E}+14$ & Cf-252 & $3.5 \mathrm{E}+13$ & Po-210 & $1.3 \mathrm{E}+13$ \\
\hline Ra-223 & $2.4 \mathrm{E}+15$ & Ra-223 & $4.1 \mathrm{E}+14$ & Ac-225 & $1.2 E+14$ & $\mid-131$ & $6.5 E+13$ & Pu-238 & 1.6E+13 \\
\hline Po-210 & $2.6 \mathrm{E}+15$ & Th-228 & $4.8 \mathrm{E}+14$ & Ra-223 & $1.7 \mathrm{E}+14$ & $\mathrm{Cm}-242$ & $7.9 \mathrm{E}+13$ & $A m-242 m$ & $2.4 \mathrm{E}+13$ \\
\hline Ra-225 & $3.0 \mathrm{E}+15$ & Ra-224 & $4.9 \mathrm{E}+14$ & Ra-225 & $1.9 \mathrm{E}+14$ & |-125 & $9.1 \mathrm{E}+13$ & $\mathrm{Cm}-242$ & $6.2 \mathrm{E}+13$ \\
\hline P-32 & $3.3 E+15$ & Ra-225 & $5.0 \mathrm{E}+14$ & P-32 & $2.1 \mathrm{E}+14$ & Ac-225 & $1.1 \mathrm{E}+14$ & Am-241 & $6.4 \mathrm{E}+13$ \\
\hline Th-228 & $3.4 \mathrm{E}+15$ & P-32 & $5.5 \mathrm{E}+14$ & $\mid-125$ & $3.3 E+14$ & Ra-225 & $1.4 \mathrm{E}+14$ & |-131 & $6.5 \mathrm{E}+13$ \\
\hline \multirow[t]{25}{*}{ I-125 } & $7.8 \mathrm{E}+15$ & |-125 & $1.2 \mathrm{E}+15$ & Ra-224 & $3.7 E+14$ & Ra-223 & $1.4 \mathrm{E}+14$ & |-125 & $9.0 \mathrm{E}+13$ \\
\hline & & Cf-252 & $1.6 \mathrm{E}+15$ & Cf-252 & $4.1 \mathrm{E}+14$ & P-32 & $1.6 \mathrm{E}+14$ & Ac-225 & $1.1 \mathrm{E}+14$ \\
\hline & & $\mathrm{Cm}-242$ & $2.1 \mathrm{E}+15$ & Cm-242 & $5.6 \mathrm{E}+14$ & Pu-238 & $2.9 \mathrm{E}+14$ & Ra-225 & $1.4 \mathrm{E}+14$ \\
\hline & & $\mathrm{Bi}-210$ & $8.9 \mathrm{E}+15$ & Pu-238 & $3.8 E+15$ & Ra-224 & $3.7 E+14$ & Ra-223 & $1.4 \mathrm{E}+14$ \\
\hline & & & & Ru-106 & $4.6 \mathrm{E}+15$ & $A m-242 m$ & $4.6 \mathrm{E}+14$ & P-32 & $1.6 \mathrm{E}+14$ \\
\hline & & & & S-35 & $4.6 \mathrm{E}+15$ & Ru-106 & $4.7 \mathrm{E}+14$ & Pu-241 & $1.7 \mathrm{E}+14$ \\
\hline & & & & Bi-210 & $5.6 \mathrm{E}+15$ & S-35 & $9.7 E+14$ & Pb-210 & $1.8 \mathrm{E}+14$ \\
\hline & & & & Am-242m & $6.0 \mathrm{E}+15$ & $\mathrm{Na}-22$ & $9.9 \mathrm{E}+14$ & $\mathrm{Na}-22$ & $2.3 \mathrm{E}+14$ \\
\hline & & & & & & Am-241 & $1.3 \mathrm{E}+15$ & Ru-106 & $2.4 \mathrm{E}+14$ \\
\hline & & & & & & Pu-241 & $2.3 E+15$ & Ra-224 & $3.7 \mathrm{E}+14$ \\
\hline & & & & & & $\mathrm{Pb}-210$ & $2.7 E+15$ & S-35 & $9.2 \mathrm{E}+14$ \\
\hline & & & & & & Ce-144 & $5.2 \mathrm{E}+15$ & Am-243 & $1.1 \mathrm{E}+15$ \\
\hline & & & & & & Te-129m & $5.2 \mathrm{E}+15$ & $\mathrm{Cm}-245$ & $1.2 \mathrm{E}+15$ \\
\hline & & & & & & Bi-210 & $5.5 \mathrm{E}+15$ & Sr-90 & $2.1 \mathrm{E}+15$ \\
\hline & & & & & & Te-127m & $6.2 \mathrm{E}+15$ & Cs-134 & $2.2 \mathrm{E}+15$ \\
\hline & & & & & & Cs-134 & $7.7 \mathrm{E}+15$ & Ce-144 & $3.1 \mathrm{E}+15$ \\
\hline & & & & & & & & Pu-239 & $3.6 \mathrm{E}+15$ \\
\hline & & & & & & & & Ti-44 & $4.8 \mathrm{E}+15$ \\
\hline & & & & & & & & Eu-154 & $5.2 \mathrm{E}+15$ \\
\hline & & & & & & & & Te-129m & $5.2 \mathrm{E}+15$ \\
\hline & & & & & & & & Bi-210 & $5.5 E+15$ \\
\hline & & & & & & & & Te-127m & $5.6 \mathrm{E}+15$ \\
\hline & & & & & & & & Eu-152 & $7.5 \mathrm{E}+15$ \\
\hline & & & & & & & & Co-60 & $7.6 \mathrm{E}+15$ \\
\hline & & & & & & & & Cs-137 & $8.7 \mathrm{E}+15$ \\
\hline
\end{tabular}

\section{The Fragmentation Beam Line}

The expected current of the uranium beam from the driver linac is 1 particle-microamp or $6 \times 10^{12} \mathrm{pps}$. Upon looking at Table 1, only ${ }^{227} \mathrm{Ac}$ and ${ }^{228} \mathrm{Th}$ production rates are below the uranium beam current. Calculations to determine the production rate of beam fragments using $\mathrm{LISE}^{2}$ indicate that less than $1 \%$ of the beam will go to any single channel, so that the Category 2 threshold should not be reached. LISE calculations also indicate a ${ }^{232} \mathrm{Th}$ beam will produce a higher production rate for the two isotopes than a ${ }^{238} \mathrm{U}$ beam. But it is the total inventory of all isotopes that matters in determining hazard categorization, so it will be desirable to remove periodically (5-10 years) certain components in the fragmentation target area in order to reduce inventory in the target building. Thus, having a storage location on site for these components will be helpful in controlling inventory buildup.

For ions of lower $Z$, the beam current from the driver increases. For a calcium beam the current will be approximately 10 particle-microamps. But from Table 1 , none of the low $\mathrm{Z}$ nuclei with Category 2 limits have production rate requirements lower than the beam current. Thus, it appears the fragmentation line should not cause RIA to be a Category 2 facility. However, it should be noted that

\footnotetext{
${ }^{2}$ http://groups.nscl.msu.edu/lise
} 
this analysis is ignoring contributions from neutrons produced when the primary interacts with the target and beam stop activating surrounding material. How significant of a factor this will be is unclear and will require more detailed calculations.

\section{ISOL}

In studying inventory issues for the ISOL system we assumed there would be a separate storage building on the RIA site so that targets would only spend 2 months in the RIA target building, one month of irradiation time and one month of temporary storage. The appropriate list of isotopes to be considered is from columns 3 and 4 of Table 1. A copper beam stop is also commonly used in the ISOL target system and would be removed much less frequently, so that the last two columns of table 1 are also appropriate to consider for low $\mathrm{Z}$ isotopes.

ANL has looked at inventories produced from uranium ISOL targets using deuteron beams (See Annual Report of the Physics Division of ANL, Section III.c.2). Their analysis looked at both a two-step target and a UC target and showed that both target systems failed to reach Category 2 inventory levels. They only assumed a target irradiation of 7 days and the target was promptly removed from the target building after irradiation. The isotope with the highest inventory level was ${ }^{131} \mathrm{I}$, which reached about $16 \%$ of the category threshold level for the two-step target. ${ }^{131}$ I has an eight day half-life, which implies that the inventory level of ${ }^{131}$ I will only be twice as great after a month of irradiation. The short half-life also means that this inventory will be reduced by a factor of 16 after a waiting period of one month.

We have also performed preliminary inventory calculations for ISOL targets. We looked at proton beams incident on UC targets and calcium oxide targets and copper beam stops. The proton beam from RIA has a higher particle current than the deuteron beam, $548 \mu \mathrm{A}$ versus $379 \mu \mathrm{A}$, and will produce a different distribution of isotopes. The calculations were based on microscopic cross sections at the initial particle energy of $730 \mathrm{MeV}$ calculated using the YIELDX ${ }^{3}$ subroutine. For the copper beam stop, cross sections at $100 \mathrm{MeV}$ were also evaluated.

For a uranium carbide target with a thickness of $5 \mathrm{~g} / \mathrm{cm}^{2}$ after 1 month of irradiation, the sum of the fractions for Category 3 for the isotopes considered (i.e., ${ }^{225} \mathrm{Ac},{ }^{227} \mathrm{Ac},{ }^{228} \mathrm{Th},{ }^{230} \mathrm{Th}$, and ${ }^{232} \mathrm{Th}$ ) was 0.37 . The sum of the fractions for Category 2 was 0.0039 .

We also looked into the possibility of a lower $\mathrm{Z}$ target producing substantial amount of the lower $\mathrm{Z}$ isotopes in Table 1 and in particular ${ }^{32} \mathrm{P}$. For a calcium oxide target with a thickness of $5 \mathrm{~g} / \mathrm{cm}^{2}$ exposed for 1 month, it was found that the amount of ${ }^{32} \mathrm{P}$ exceeded the Category 3 threshold. A $548 \mu \mathrm{A}$ beam of protons produces $1.6 \times 10^{12}$ atoms of ${ }^{32} \mathrm{P}$ per second. The mass of ${ }^{32} \mathrm{P}$ at the end of irradiation is $1.2 \times$ $10^{-4} \mathrm{~g}$, which is 2.7 times its Category 3 threshold of $4.2 \times 10^{-5} \mathrm{~g}$. The sum of the fractions for Category 3 for all isotopes considered (which were those isotopes with an atomic number less than that for calcium or oxygen) was 2.9. The sum of the fractions for Category 2 was 0.0082 . The production rate of ${ }^{35} \mathrm{~S}$ is $7.3 \times 10^{11}$ atoms/s.

The copper beam stop also contributes to inventory. The thickness of copper required to slow $730 \mathrm{MeV}$ protons to $100 \mathrm{MeV}$ was calculated to be $290 \mathrm{~g} / \mathrm{cm}^{2}(32 \mathrm{~cm})$. The cross sections were evaluated at both $730 \mathrm{MeV}$ and $100 \mathrm{MeV}$, and the larger cross section was used for simplicity and conservatism. For a

\footnotetext{
${ }^{3}$ The YIELDX subroutine is available from Abdulnasser.F.Barghouty@nasa.gov.
} 
copper beam stop exposed to a $548 \mu \mathrm{A}$ beam of protons for 20 years, the Category 2 fraction is 0.34 . The isotope with the largest contribution to this fraction is ${ }^{32} \mathrm{P}$ at 0.18 , with $95 \%$ of its steady state activity reached at 2 months of irradiation.

Based on the information presented here, we believe the ISOL targets area will not cross the Category 2 limits assuming that a separate storage location is part of RIA. Without this ability to remove targets from the RIA target buildings inventories of long-lived actinide isotopes may approach the Category 2 threshold level. The release fraction of the actinium and thorium isotopes should be low such that these activities stay in the ISOL target and can removed when the target is removed. Lower $Z$ targets also do not appear to cross Category 2 levels, though more work in this area is warranted.

\section{Conclusion}

The question of whether the RIA facility will be classified as a nuclear facility or as an accelerator facility only cannot be determined from analysis alone due to the allowances of the regulations and the approach that the DOE Office of Science has taken with SNS. Simplistic scoping calculations for proton beams on various targets indicate that the RIA facility is most likely to be a Category 3 nuclear facility, but could produce Category 2 quantities of radioisotopes only after many years of operation. The use of segmentation can be used to limit the Category 2 requirements to only the storage building, leaving the target building and, possibly, the experimental hall classified as Category 3 , and the driver linac as an accelerator facility. Isotopes that do not have Category 2 thresholds defined were not considered in this analysis. 


\section{Appendix 1 - Some Differences Between Category 2 and Category 3 Nuclear Facilities}

It should be noted that the hazard categorization process involves both an initial hazard category and a final hazard category. The initial hazard category determines the documentation requirements for the safety analysis. The final hazard category determines the physical and operational requirements for the facility. A Category 2 facility requires a complete 17 chapter DSA following the requirements of DOESTD-3009, whereas a Category 3 facility requires only a minimum level of detail for many of the chapters.

The physical and operational requirements for the facility are based on the hazard controls necessary to eliminate, limit, or mitigate hazards to workers, the public, or the environment, including

(1) Physical, design, structural, and engineering features;

(2) Safety structures, systems, and components (SSCs);

(3) Safety management programs;

(4) Technical safety requirements; and

(5) Other controls necessary to provide adequate protection from hazards.

The physical requirements of a Category 2 facility include both "safety class" and "safety significant" structures, systems, and components (SSCs). The safety-class designation has been traditionally reserved for SSCs needed for public protection and carries with it the most stringent requirements (e.g., enhanced inspection, testing and maintenance, and special instrumentation and control systems). Safety class SSCs require design against performance category 3 (PC3) criteria. A Category 3 facility is likely to have no safety class SSCs, and the number of safety-significant SSCs, if any, will be less than that of a Category 2 facility. Safety-significant SSCs are those of particular importance to defense in depth or worker safety, but do not require meeting the level of stringency associated with safety-class SSCs. Safety significant SSCs require design against performance category 2 (PC2) criteria. Guidelines for the performance categorization of SSCs for the purpose of mitigating natural phenomena hazards are provided in DOE-STD-1021-93, Natural Phenomena Hazards Performance Categorization Guidelines For Structures, Systems, And Components, while design and evaluation criteria for performance categories are provided in DOE-STD-1020-2002, Natural Phenomena Hazards Design And Evaluation Criteria For Department Of Energy Facilities.

The operational requirements of Category 2 and Category 3 nuclear facilities are described by technical safety requirements (TSRs). TSRs are the limits, controls, and related actions that establish the specific parameters and requisite actions for the safe operation of a nuclear facility and include, as appropriate, safety limits, operating limits, surveillance requirements, administrative and management controls, use and application provisions, and design features. In general, the greater the number of safety SSCs, the greater the number of TSRs.

If RIA is declared to be an accelerator facility only and not a nuclear facility, then it would be outside the scope of 10 CFR 830 . DOE management at their discretion may then decide to voluntarily impose nuclear facility requirements on RIA, and the conditions and requirements associated with that decision are also at the discretion of DOE management. In other words, they can pick and choose what nuclear facility requirements they will apply to RIA. For example, they may choose to declare the RIA as a Category 2 nuclear facility but only prepare the DSA for a Category 3 facility, not adopt all of the QA sections of subpart A, implement a USQ process, and implement a minimal TSR. 
Summary of Nuclear Safety Requirements by Hazard Category

\begin{tabular}{|c|c|c|c|c|c|}
\hline & $\begin{array}{l}\text { Category } 2 \\
\text { Nuclear } \\
\text { Facility }\end{array}$ & $\begin{array}{l}\text { Category } 3 \\
\text { Nuclear } \\
\text { Facility }\end{array}$ & $\begin{array}{l}<\text { Category } 3 \\
\text { Nuclear Facility } \\
\text { (Formerly } \\
\text { Radiological) }\end{array}$ & $\begin{array}{l}\text { Rare Isotope } \\
\text { Accelerator } \\
\text { Facility }\end{array}$ & $\begin{array}{l}\text { Nonnuclear } \\
\text { Facility }\end{array}$ \\
\hline $\begin{array}{l}\text { 1. Subject to Price-Anderson Amendment Act } \\
\text { Enforcement Provision, } 10 \text { CFR } 820\end{array}$ & Yes & Yes & Yes & Yes & Yes \\
\hline $\begin{array}{l}\text { 2. Subject to } 10 \text { CFR } 830 \text { Subpart A QA } \\
\text { Requirements }\end{array}$ & Yes & Yes & Yes & $\begin{array}{c}\text { Yes if } \\
\text { declared } \\
\text { nuclear } \\
\text { facility }\end{array}$ & No \\
\hline $\begin{array}{l}\text { 3. Subject to } 10 \text { CFR } 830 \text { Subpart B Nuclear } \\
\text { Safety Requirements }\end{array}$ & Yes & Yes & No & $\begin{array}{c}\text { Depends on } \\
\text { hazard } \\
\text { category }\end{array}$ & No \\
\hline $\begin{array}{l}\text { 3.1 Prepare Documented Safety Analyses } \\
\text { (DSA) According to DOE-STD-3009 }\end{array}$ & Yes & Yes & No & $\begin{array}{c}\text { Depends on } \\
\text { hazard } \\
\text { category }\end{array}$ & No \\
\hline $\begin{array}{l}\text { 3.1.1 Prepare Full DOE-STD-3009 DSA } \\
\text { (Chapters 1-17) }\end{array}$ & Yes & No & N.A. & $\begin{array}{c}\text { Depends on } \\
\text { hazard } \\
\text { category }\end{array}$ & N.A. \\
\hline $\begin{array}{l}\text { 3.1.2 Prepare Partial DOE-STD-3009 DSA } \\
\text { (Chapters 2, 3, 4, and 5) }\end{array}$ & No & Yes & N.A. & $\begin{array}{c}\text { Depends on } \\
\text { hazard } \\
\text { category }\end{array}$ & N.A. \\
\hline $\begin{array}{l}\text { 3.2 Establish Unreviewed Safety Question } \\
\text { (USQ) Process }\end{array}$ & Yes & Yes & No & $\begin{array}{c}\text { Depends on } \\
\text { hazard } \\
\text { category }\end{array}$ & No \\
\hline $\begin{array}{l}\text { 3.3 Develop Technical Safety Requirements } \\
\text { (TSR) }\end{array}$ & Yes & Yes & No & $\begin{array}{c}\text { Depends on } \\
\text { hazard } \\
\text { category }\end{array}$ & No \\
\hline $\begin{array}{l}\text { 4. Subject to } 10 \text { CFR } 835 \text { Radiation } \\
\text { Protection Requirements }\end{array}$ & Yes & Yes & Yes & Yes & Yes \\
\hline
\end{tabular}

